\title{
Gun crime incident reviews as a strategy for enhancing problem solving and information sharing 1
}

\author{
Natalie Kroovand Hipple* \\ Assistant Professor \\ Indiana University \\ Edmund F. McGarrell \\ Professor \\ Michigan State University \\ Mallory O’Brien \\ Assistant Professor \\ Medical College of Wisconsin \\ Beth M. Huebner \\ Professor \\ University of Missouri - St. Louis
}

*Corresponding author:

Natalie Kroovand Hipple

Assistant Professor

Indiana University

1033 East Third Street

309 Sycamore Hall

Bloomington, IN 47405

nkroovan@indiana.edu (e)

812.856 .2759 (o)

812.855 .5522 (f)

${ }^{1}$ This project was supported by Award No. 2013-R2-CX-0015, awarded by the National Institute of Justice, Office of Justice Programs, U.S. Department of Justice. The opinions, findings, and conclusions or recommendations expressed in this publication are those of the author(s) and do not necessarily reflect those of the Department of Justice.

The Version of Record of this manuscript has been published and is available in the Journal of Crime and Justice March 9, 2016 http://www.tandfonline.com/doi/full/10.1080/0735648X.2016.1155303 


\title{
Gun crime incident reviews as a strategy for enhancing problem solving and information sharing
}

\begin{abstract}
Over the last several decades, police departments and other criminal justice agencies have seen a shift toward a proactive problem-solving response to crime problems. This problem solving orientation has often included an emphasis on expanded partnerships across criminal justice agencies as well as with a variety of community stakeholders, including researchers. This manuscript uses the issue of gun violence as a lens through which to examine the organizational and inter-organizational changes necessary to apply a data-driven, proactive, and strategic policing-led response to gun homicides and non-fatal shootings in four Midwestern sites. Each site adapted a unique data collection process and incident review. The data collection, incident reviews, and the varying models developed across the four cities, provide a reflection on corresponding organizational and inter-organizational changes that illuminate the movement toward this proactive, data-driven, problem solving model of criminal justice. Fulfilling the promise of the incident reviews, however, requires internal organizational and cross-agency inter-organizational collaboration to align people, systems, and resources with this proactive, problem-solving model. Additionally, effectively implementing these organizational and interorganizational changes appears dependent on commitment and leadership, collaboration and partnerships, data quality and availability, and training and communication within and across organizational boundaries.
\end{abstract}

Keywords: incident reviews, gun violence, non-fatal shootings, problem solving

\section{$\underline{\text { Author bios }}$}

Natalie Kroovand Hipple is an assistant professor in the Department of Criminal Justice at Indiana University. Hipple's research interests include gun violence, police problem solving, evaluation of criminal justice programs, and restorative justice.

Edmund F. McGarrell is a professor in the School of Criminal Justice at Michigan State University. McGarrell's research focuses on communities and crime, policing, and violence prevention. He serves as the research partner in Detroit Ceasefire.

Mallory O'Brien is an assistant professor in the Institute for Health and Society at the Medical College of Wisconsin. O'Brien's areas of research include violence prevention, gun violence, domestic violence and data integration.

Beth M. Huebner is a professor and graduate director in the Department of Criminology and Criminal Justice at the University of Missouri-St Louis. Her principal research interests include the collateral consequences of incarceration, patterns of recidivism, and public policy. 


\section{Gun crime incidents reviews as a strategy for enhancing problem solving and information sharing}

Over the last several decades, police departments and other criminal justice agencies have seen a shift toward a proactive problem-solving response to crime problems. This problem solving orientation has often included an emphasis on expanded partnerships across criminal justice agencies as well as with a variety of community stakeholders, including researchers (Roehl et al. 2008). Indeed, several scholars witnessing these trends labeled this the "new criminal justice' and have argued that the criminal justice system's response to crime is no longer a simple reactive and linear process of case processing from police to courts to corrections (Klofas, Hipple, and McGarrell 2010). Rather, the police are increasingly working with coalitions of agencies and organizations that pool their powers to serve crime reduction goals, are concentrating on fundamentally local problems and issues, and are increasingly data-driven and research based. And, for many reasons, local law enforcement most often must be the leaders in strategic responses to crime problems.

Although these shifts are not uniform across cities or criminal justice agencies, there are abundant signs of an increasing emphasis on goals and methods that emphasize a more proactive and problem solving mission. These include studies of the impact of problem solving initiatives focused on policing (e.g., Braga and Weisburd 2010), community supervision (e.g., Hawken and Kleiman 2009), and specialized courts (e.g., Mitchell et al. 2012b, Sevigny, Fuleihan, and Ferdik 2013). And, while there is great variation, there is evidence that proactive initiatives can reduce crime and criminal involvement. Traditionally, this research has focused on the outcomes of crime interventions, and researchers have yet to describe in detail the organizational processes needed to adopt these models, particularly using an organizational theory lens. This paper seeks 
to contribute to our knowledge about the efficacy of the problem solving model in policing by examining one type of process focused on one specific problem in four distinct jurisdictions.

Specifically, this manuscript uses the issue of gun violence as a lens through which to examine the organizational and inter-organizational changes necessary to apply a data-driven, proactive, and strategic policing-led response to gun homicides (GH) and non-fatal shootings (NFS). This multi-jurisdictional case study (Creswell 2012) focuses on an innovative process for studying gun violence across four cities with medium to high levels of gun violence.

Specifically, the manuscript will describe the innovative implementation of crime incident reviews (Klofas et al. 2006) spearheaded by local police departments to address gun-related crime. Data come from four cities: Detroit, Indianapolis, Milwaukee, and St. Louis. Although the implementation goals were the same, each site adapted a unique data collection process and incident review process (three sites). The data collection, incident reviews, and the varying models developed across the four cities, provide a reflection on corresponding organizational and inter-organizational changes that illuminate the movement toward this proactive, data-driven, problem solving model of criminal justice.

\section{Background and related research}

\section{Problem solving movement}

In the late 1970s, Herman Goldstein called for a fundamental shift in how the police think about their response to crime (Goldstein 1990, 1979). Rather than general strategies (e.g., randomized patrol) and a focus on responding to crime incidents (e.g., enhanced response times, clearance rates), Goldstein argued that the police needed to think about addressing specific categories of problems. Building on research demonstrating recurring patterns of different crime types (e.g., business burglaries during nighttime in contrast to daytime burglaries of residences; 
intimate partner violence in contrast to assaults in bars and taverns), the problem solving model emphasized that crime prevention and control would be advanced much more effectively by improving responses to problem types as opposed to improved processing of individual cases. With the introduction of tools like the SARA (Scanning, Analysis, Response, and Assessment) Model (Eck and Spelman 1987), individual police officers were empowered to problem solve on their own. Using four steps, the SARA model helped guide police to identify problems, determine their underlying causes, and implement and assess evidence-based responses to those problems.

It appears that research on the problem solving model itself has largely occurred in the context of policing. And, although research demonstrates promise across the problem solving initiatives (Braga 2008, Braga and Weisburd 2010, Hawken and Kleiman 2009, Henry and Kralstein 2011, Mitchell et al. 2012a, Sevigny, Fuleihan, and Ferdik 2013), at least in the context of policing there is also evidence that problem solving models like the SARA model are not always implemented as intended. For example, Cordner and Biebel (2005) studied problem solving in the San Diego Police Department, considered leaders in problem solving policing, and found a significant gap between the 'Goldstein' model and the actual practice of problem solving (see also Braga and Weisburd 2006, Capowich and Roehl 1994, Tilley 1999). Specifically, there was a tendency to focus on individual problems (a problem person or a problem place) as opposed to groupings of problem types spanning blocks, neighborhoods, or a police beat. They also found that the analysis of the problem and impact assessment was often very limited. And, despite having an established crime analysis unit, there appeared to be limited involvement of crime analysts in the problem solving efforts. There was also tendency to focus on drug and disorder problems to the exclusion of problems associated with property and violent crimes. That 
is, officers believed problem solving policing was most effective when applied to less serious or "soft" crimes such as drug and disorder problems and was not really applicable to all crimes, especially serious crime. Cordner and Biebel (2005) found a reasonably high level of support for problem solving but there was variation among officers consistent with other research that has found that problem solving may be limited to particular officers or units (Cordner and Biebel 2005, Skogan et al. 1999, Toch and Grant 1991).

In the context of the present research on gun crime, the problem solving efforts move beyond individual officers to multiple units within the police department working in partnership with other criminal justice agencies. Additionally, the limitations of traditional police data sources for studying gun crime requires that the problem solving analysis consider innovative approaches to analyzing the gun crime problem. Absent such innovation and organizational adaptations, problem analysis will be based on limited and selective incidents (e.g., homicides) and on limited information about the people, groups, places, and contexts of the incidents.

\section{Organizational and Inter-organizational Dimensions}

Problem solving approaches in policing, prosecution, judicial and corrections contexts include internal organizational changes as well as collaboration across organizations. At the organizational level, the police have traditionally responded to calls for service, investigated alleged crimes, and made arrests tied to specific incidents. Prosecutors screen arrests and determine whether there is sufficient evidence to prosecute. The courtroom workgroup (prosecution, defense, judges and court staff) handles specific cases to determine guilt or innocence and allocate sentences. Corrections staff then handle the individual offender according to the terms of his or her sentence (community sanctions, supervision, and/or incarceration). As such, criminal justice personnel who have traditionally worked as part of 'people processing' 
organizations (Hasenfeld 1972, Hasenfeld and Cheung 1985) responding to specific incidents, cases, and defendants, are now being asked to address persistent problems. This requires changes in orientation, work processes, communication patterns, and measures of organizational success.

As with all public bureaucracies, criminal justice agencies tend to resist change (Allen 2002, Miller, Ohlin, and Coates 1977) and thus the move toward a problem solving model is not automatic and implementation is likely to be a challenge (Skogan and Hartnett 1997). As mentioned earlier, despite a long term commitment to problem solving including training, organizational incentives, a robust crime analysis unit, and a data system for documenting problem solving activities, San Diego is an example of the difficulty of implementing a different way of doing business (Cordner and Biebel 2005) (see also Skogan et al. 1999, Toch and Grant 1991). ${ }^{1}$ This organizational resistance is compounded by the reality that all the affected organizations retain responsibility to their own day to day missions, to respond to calls from the public, and to process individual cases.

\section{Incident Reviews}

Systematic incident reviews, typically focused on homicides, have developed as an approach to fill the gap in traditional information systems. Gun crime incident reviews build upon processes developed in public health. Specifically, public health researchers have utilized systematic mortality incident reviews to advance knowledge and improve practice in relation to fetal, infant, child, and maternal deaths (Hutchins, Grason, and Handler 2004). The public health reviews were developed to address limitations in the scope and timeliness of existing data systems. The reviews seek 'to improve the understanding of personal, social, and community as well as

\footnotetext{
${ }^{1}$ Braga and Weisburd (2006) offer the interesting observation that even with limited analysis there is evidence of problem solving efforts having a positive effect on crime and public safety.
} 
medical factors associated with adverse reproductive and infant health outcomes at the local level' (Hutchins, Grason, and Handler 2004, 259).

Although problem solving generally, and incident reviews as an analytical component of problem solving, can logically occur within single organizations, experience suggests these initiatives often occur in an inter-organizational context (Azrael, Braga, and O'Brien 2013, Braga et al. 2001, Klofas et al. 2006). Typically, incident reviews are part of expanded interorganizational linkages as the goal is to bring multiple perspectives and multiple sources of information to the review. With respect to policing, problem solving efforts typically call for establishing partnerships with local residents and neighborhood associations, business owners, code enforcement, utilities, and social services. Ideally, incident reviews include a variety of agency stakeholders that may have 'touched' the individuals (suspects, victims) and the groups or networks connected to the incident, the location of the incident, or have more general insight into the nature of the problem. Thus, successfully implementing crime incident reviews involves securing the support and cooperation of multiple units within and across multiple agencies. Those involved believe these partnerships provide additional sources of information (e.g., probationer and parolee information) as well as additional resources for addressing recurring problems (e.g., focused prosecution, code enforcement, Crime Prevention Through Environmental Design [CPTED] strategies). Milwaukee

The emphasis on inter-agency collaboration to support both problem solving and crime incident reviews suggests an increased 'coupling' of what is typically seen as a loosely coupled system (or non-system) (Duffee 1980, Wright 1981). That is, rather than simply moving cases along the various components of the criminal justice system, problem solving and crime incident reviews attempt to foster information sharing about recurring problems across multiple agencies 
and stakeholders. Ideally, the information sharing leads to deeper understanding of the drivers of the crime problem and improved responses in terms of crime prevention and public safety.

The Boston Gun Project provides the first documented example of systematic incident reviews used as a key analytic process in criminology (Braga et al. 2001). Also referred to as Boston Ceasefire, this multi-agency initiative partnered criminal justice personnel with a research team that followed a problem solving model that included systematic incident reviews of gun homicides involving youths. The incident reviews led to new insights about the nature of youth gun violence in Boston. Specifically, gun crime was highly concentrated among a small proportion of the youth population, victims and suspects overlapped across a number of dimensions, and youths involved in violent street groups were at considerably heightened risk for offending and victimization (Braga et al. 2001). These characteristics became the emphasis of the Boston Ceasefire focused deterrence intervention.

The success of Boston Ceasefire led to the adoption of systematic incident reviews in a series of similar problem solving violence prevention and control initiatives including the Strategic Approaches to Community Safety Initiative (SACSI) (Roehl et al. 2008) and Project Safe Neighborhoods (PSN) (Klofas et al. 2006). The incident reviews sought to combine street level intelligence from a variety of criminal justice sources to increase the understanding of the nature of gun crime and to inform local prevention and control strategies. That way, criminal justice officials could strategically focus limited resources for maximum effectiveness. Secondary benefits could include information to support investigations and clear cases and to identify system gaps or failures.

It is difficult, however, to analyze the impact of incident reviews because they are typically associated with specific interventions such as Boston Ceasefire, SACSI, or PSN (e.g., 
Braga et al. 2001, Klofas et al. 2006, McGarrell et al. 2010, McGarrell et al. 2006). An

exception, however, is the evaluation of the Milwaukee Homicide Review Commission (Azrael, Braga, and O'Brien 2013). For purposes of the evaluation, the incident reviews focused on particular police districts (treatment sites) and found reductions in gun crime. Specifically, the treatment police districts observed over a 50 percent reduction in homicides that was statistically significant when compared to a nine percent reduction in the control districts (Azrael, Braga, and O'Brien 2013). Additionally, over a two and one-half year period, the Milwaukee Homicide Review Commission developed over 100 recommendations aimed at reducing homicides. These recommendations ranged from single agency recommendations such as recommending the police department increase patrols to problem taverns (reviews indicated 10 percent of homicides occurred in or directly outside a tavern) to co-locating Wisconsin Department of Corrections agents in the police district stations to allow for closer client supervision and improved policeagent collaboration. The Governor's Office funded this recommendation (O'Brien, Woods, and Cisler 2007).

\section{Gun violence}

In the instance of addressing gun crime, the lack of readily available data sources on gun crime incidents severely limits the ability of research to contribute to the understanding of gun violence and the development of evidence-based strategies for reducing gun violence. In 2005, the National Research Council's Committee on Law and Justice noted that information on gunrelated violence was far too limited and fragmented to provide "accurate, complete, timely, and detailed data on the incidence and characteristics of gun-related violence" $(2005,20)$. Historically, police incident data in the form of the Uniform Crime Reporting (UCR) system have provided descriptive data on gun crime limited largely to homicides. The Supplemental 
Homicide Reporting (SHR) system provides more details on homicides and both the SHRs and National Incident Based Reporting Systems (NIBRS) allow for the isolation of incidents involving guns. However, there is a considerable time delay before SHRs are available for analyses and NIBRS systems remain the exception rather than the rule for most jurisdictions in the United States as roughly one-third of law enforcement agencies participating in UCR reported via NIBRS in 2013 (Federal Bureau of Investigation 2015a). Even when focused on homicides in jurisdictions covered by SHR and NIBRS systems, researchers have questioned the reliability and validity of gun crime data elements such as victim-offender relationships and incident characteristics like gang involvement or intimate partner violence (e.g., Braga et al. 1999, Loftin 1986, Loftin et al. 2015, Riedel 1990, Williams and Flewelling 1987, Maxfield 1989). The additional limitation of the SHR's is the absence of data to study NFS.

The current study focuses on data collection and problem solving efforts to better address gun violence through the use of systematic crime incident reviews. The study benefits by examining gun violence data collection and incident reviews efforts across four jurisdictions. Consequently, it provides the opportunity to examine similarities and differences across four jurisdictions, trade-offs associated with varying approaches to the incident reviews and their implementation, and consideration of the organizational and inter-organizational dimensions of systematic incident reviews as a component of problem solving.

\section{The Project}

In 2014, the authors embarked on a 30-month project funded by the National Institute of Justice. The overarching goals of this project included both improvements in gun violence information systems as well as advancing basic knowledge about gun violence. Specific goals included: increasing understanding of the spatial and network dimensions of gun violence; 
creating a better understanding of NFS and how they relate to GH; and, improving data systems on gun violence. The research team proposed a 'ground-up' approach, working with four midwestern police departments to combine GH and NFS incidents into common databases and to supplement incident reports through a variety of data sources, with the main supplemental mechanism being crime incident reviews (Klofas et al. 2006). The initial project included Detroit, Indianapolis, and Milwaukee. St. Louis was added as the fourth site mid-way through the project and, while gun crime data collection was a priority in St. Louis, implementing crime incident reviews was not due to the shortened project time frame.

Table 1 displays the violent crime and homicide rates for the four study sites. Detroit and St. Louis are similar in their crime rates and are consistently ranked among the cities with the highest violent crime and homicide rates in the United States. Indianapolis and Milwaukee experience more moderate rates of violent crime, though both cities have rates over three times the national average for metropolitan jurisdictions.

\section{[INSERT TABLE 1 ABOUT HERE]}

Each site had a local research partner who was charged with data collection and coordinating and implementing crime incident reviews to fit the local context. The crime incident review process was rooted in the Milwaukee Homicide Review Commission process (O'Brien, Woods, and Cisler 2007). And, as expected, each site had its own specific data collection and review methodology based on existing data systems and the wants and needs of the local police organization. The overarching research question of this study is to what extent can gun crime incident reviews contribute to our understanding of gun crime and contribute to problem solving prevention initiatives? With this broad question in mind, the research questions informing the current analysis include: 
RQ1: How have incident reviews developed in these jurisdictions?

RQ2: What are the similarities and differences across the three jurisdictions in the incident reviews?

RQ3: What are the relative advantages and disadvantages of these approaches to the incident reviews?

RQ4: What are the benefits and the challenges of the incident reviews?

RQ5: What are the implications for organizational and inter-organizational and implementation dimensions necessary for the effective use of gun crime incident reviews?

\section{Findings}

All four sites have similar, long histories of federally supported multi-agency crime reduction efforts including SACSI, PSN, and the Comprehensive Anti-Gang Initiative (CAGI). Milwaukee has been conducting homicide reviews since 2005. Indianapolis conducted incident reviews during the SACSI project but had since discontinued the reviews. Indianapolis reinstituted crime incident reviews in late 2012, around the same time that Detroit embarked on reviews. The incident reviews were an important component for the current project. Although St. Louis does not conduct homicide or NFS reviews specifically, there is a long history of CompStat within the St. Louis Police Department. Consequently, St. Louis offers a valuable contrast to the other three cities and is likely representative of major city police departments that has not yet begun a formal process for homicide or NFS incident reviews.

\section{Incident review development}

In three sites, the development of incident reviews coincided with data collection efforts. As expected, the police departments at each site collected and maintained robust data pertaining to GH and they were able to extract homicide information easily to provide to the researchers. These data included victim and offender information, and case details such as location and 
motive. In contrast, with the exception of Milwaukee, none of the sites could provide accurate data on NFS. Therefore, the priority became establishing a system for collecting data on NFS if there was not one. The incident review process would be part of this; however, due to the volume of NFS at each site, NFS reviews would serve to supplement a larger NFS data collection method.

Beginning in late November 2013, the 'Detroit Ceasefire' team began holding weekly incident reviews covering all gun crime incidents in two police precincts that had among the highest levels of gun crime in the city. The gun crime incident reviews were developed as part of a gun violence prevention initiative modeled on the problem solving component of Boston Ceasefire. The Detroit Ceasefire team agreed to follow this model and to use systematic incident reviews of gun crime incidents as the key analytical component of its ongoing problem solving intended to identify the drivers of gun crime violence in the 5th and 9th Precincts. As was the case in Milwaukee, as a National Incident Based Reporting System (NIBRS) jurisdiction², Detroit was able to query the DPD records management system to identify aggravated assaults with a gun involving an injury. However, in order to meet the goals of timely identification of all NFS, it was necessary for a member of the research team to manually read aggravated assaults, armed robberies, carjackings and other firearms-involved incidents in order to identify and accurately count NFS in a real-time environment.

Indianapolis reinstituted incident reviews in 2012 after years without them. Recognizing that NFS were approximately four times as common as GH, and noting the limited information available about NFS, a small multi-agency working group decided to attempt NFS incident reviews after a change in leadership. The reviews would supplement a citywide NFS data

\footnotetext{
${ }^{2}$ As of 2013, Detroit and Milwaukee were NIBRS jurisdictions. Indianapolis and St. Louis were not (Federal Bureau of Investigation 2015a).
} 
collection effort and review incidents would be a selection of NFS occurring in one zip code. This zip code was selected based on an analysis of historical criminal homicide data and the increased risk for young black males living in this geographic area to become a homicide victim. While there were no NFS data to supplement the homicide data at that time it was reasonable to assume that NFS would follow the same geographic and victim patterns.

Indianapolis does not proactively search police incident records management systems for NFS incidents. Instead, the research team is notified about NFS incidents via an internal police document that is completed by Aggravated Assault and Homicide detectives, usually within 24 hours of a homicide or NFS. This internal document is the beginning point for data collection on all NFS. After receiving the internal document, the research team manually verifies all NFS like the other sites using available records management systems.

Milwaukee developed a multi-agency homicide review process in 2005, and PSN grant funds supported the first Milwaukee homicide reviews (http://city.milwaukee.gov/hrc). Initially the homicide reviews occurred in three of the seven police districts and then expanded citywide in 2008. In an effort to learn more about firearm violence, NFS associated with homicides were incorporated into the reviews in 2006. Milwaukee's commitment to NFS reviews was an extension of their long, uninterrupted commitment to homicide incident reviews. Milwaukee is similar to Detroit in that the research team proactively searches the police incident report records management system for NFS. In addition to verifying each incident, the research team also searches police calls for service data looking for incidents they might have missed.

This project allowed for some fine-tuning of the review process at each site. In Detroit, observations that many homicide and non-fatal shooting suspects and victims had prior carrying a concealed weapon $(\mathrm{CCW})$ charges led to an expanded gun crime definition to include $\mathrm{CCW}$ 
arrests. Likewise, Indianapolis adjusted its NFS review case selection process several times since this project started. Each change was made to address 'missed' cases, which are cases participants felt were not being reviewed but should be.

And, most recently, Milwaukee, the site with crime incident reviews in place the longest, has changed the NFS reviews to focus on the most frequent perpetrators of gun violence and their associates. This change in case selection was intended not only to focus on the individuals most likely to be involved in gun violence but to also improve information sharing and intelligence on these individuals. Additionally, participation was expanded to include additional federal criminal justice partners (ATF, FBI).

\section{[INSERT TABLE 2 ABOUT HERE]}

\section{Incident review structure}

All four sites captured homicide and NFS data citywide but there were differences in the types of reviews conducted and how the reviews were structured (see Table 2). Milwaukee conducts both monthly homicide reviews focused on city-wide incidents and bi-weekly NFS reviews focused on a sample of NFS based on the meeting location (e.g. a meeting at the $3^{\text {rd }}$ District police station focused on a sample NFS occurring in the $3^{\text {rd }}$ district). NFS cases have been selected by the districts, investigation bureau, or by MHRC staff; criteria have varied from hotspots to gangrelated to drug-related to robberies, the focus is driven by the stakeholders.

Indianapolis limited the focus of its monthly reviews to NFS using a triage approach to focus only on criminal NFS (accidental and self-inflicted NFS were excluded). In contrast to Milwaukee and Indianapolis, Detroit conducts weekly reviews focusing on all gun crimes in two contiguous police precincts. Gun crimes were defined to include homicides, non-fatal shootings, aggravated assaults with a firearm (i.e., shootings that did not result in a victim being struck; 
brandishing), armed robberies, and carjackings, and as noted earlier, CCW arrests. In essence, and consistent with the variation in geographic and crime focus, Detroit conducted weekly reviews with significantly more incidents while both Indianapolis and Milwaukee focused on a smaller number of incidents during monthly NFS reviews (Indianapolis), monthly homicide reviews, and bi-weekly NFS reviews (Milwaukee).

The distinctions also related to the preparation for the reviews. Given the bi-weekly or monthly frequency, Indianapolis and Milwaukee distributed case lists approximately one week before the review and prepared PowerPoint summaries to guide the review meeting. In Detroit, given the weekly frequency, the research team prepared case summaries and distributed them two days before the review. In Milwaukee and Indianapolis, police department officials provided case summaries and then the discussion was guided by the research team. In Detroit, officials from the police department guided the review discussions.

The reviews in the three sites were structured quite similarly in terms of participation And, while exact review attendees varied from meeting to meeting, by crime review type (GH or NFS), and by site, there were common partnerships represented across the three sites. Table 3 displays the partners who regularly and occasionally participated in reviews at each site. All three sites' reviews included representation of federal, state and local partners. Although there were slight differences across the three sites, for example, Detroit and Milwaukee had more participation from federal law enforcement agencies, these variations tended to reflect differences in the structure of each organization. Occasional participation by some partners reflected both the cases being reviewed as well as resource availability. As expected, police department representation was significant at all sites. Table 3 also includes a more detailed list of police department attendees. All three sites included regular involvement from street level 
officers and at least occasional involvement among command staff, homicide and/or major crimes investigators. Detroit and Indianapolis included special units such as gang and intelligence with Indianapolis also including the juvenile unit.

\section{[INSERT TABLE 3 ABOUT HERE]}

All three sites included local prosecutors as well as combinations of probation and parole, community corrections, and the Department of Corrections. Some of the local level variations included Detroit incorporating the state police, Indianapolis incorporating the crime lab, Milwaukee and Indianapolis occasionally incorporating jail staff, and both Indianapolis and Milwaukee including personnel from fusion intelligence centers. Whereas Indianapolis included the juvenile unit from the lead police department (IMPD), both Detroit and Indianapolis included school police.

All three sites included research teams in the incident reviews. The teams consisted of a lead researcher affiliated with a local university and at least one research assistant. As noted earlier, the research team did considerable preparation for the reviews at each site. The research team also provided input and facilitated discussion as well as captured the data generated in the reviews. Follow-up questions were tailored to each site and their operational and data collection needs. For instance, Detroit had a specific interest in group and gang activity as it related to their gun crime incidents. Indianapolis tended to focus on repeat individuals (i.e., involved in multiple NFS in any role) and locations. Milwaukee often posed the question of whether anything could have been done to prevent the incident from occurring. Additionally, Detroit and Milwaukee included civilian project coordinators and outreach workers. In the case of Detroit, these were individuals responsible for Detroit Ceasefire whereas in Milwaukee these were individuals who 
were part of the Milwaukee Homicide Review Commission and employed by the Milwaukee Health Department, Office of Violence Prevention.

\section{Benefits}

As expected, there are advantages and disadvantages to the way in which each site conducted their reviews (see Table 4). As each site tailored their reviews to their local context, they had to take into consideration issues related to time sensitivity (i.e., operational and tactical responses), resource constraints (i.e., human and data), amount and detail of information related to gun crime (i.e., cross-district, cross-case). Thus, Indianapolis and Milwaukee prioritized strategic intelligence through less frequent but more comprehensive reviews of a smaller universe of incidents. Detroit prioritized tactical intelligence to support timely prevention actions through weekly reviews of a larger volume of incidents. The tradeoff for Detroit was often very limited information about incidents whereas the tradeoff for Indianapolis and Milwaukee was the potential loss of opportunity to intervene for prevention purposes. As time passed, each site adjusted its review structure as needed but involving tradeoffs in the relative advantages and disadvantages summarized in Table 4.

\section{[INSERT TABLE 4 ABOUT HERE]}

The observed benefits of the incident reviews include those both internal and external to the police department. However, generally speaking, a benefit that affected the police department also carried external benefits to other participating agencies. For example, the reviews encouraged a significant change in communication and information sharing at all levels across all agencies. That is, all sites saw communication and information sharing benefits both intraand inter-agency. And, in this context, 'information' could mean a wide variety of things. Certainly, information could include official data coming from agency records management 
systems. At the same time, information could also be lead information, information from a field notebook, or acquired from a citizen, unofficial in nature, and not recorded in any formal records management system.

The very nature of the multi-unit (i.e., within the police department) and multi-agency partnerships increased information sharing. The reviews served as a forum where units and officers who did not usually work side by side or regularly interact could share information about the gun crime incidents. The review meetings created the same opportunity for agencies across the state, local, and federal criminal justice system to share information with the local police department and other agencies. Agencies such as probation and parole could share information about the involvement of their clients and add to gang information from intelligence gathered in jails and prisons. State and federal prosecutors could glean information about cases they may decide warrant increased attention and consider the benefits of state versus federal prosecution. They could also inform law enforcement partners about information they need to successfully prosecute cases. And, communication that occurred outside the reviews increased as well as a result of the relationships established through the review process.

Given the difficulty in collecting data specifically relating to NFS, the review process served as a good supplement to the data collection processes at all sites even though reviewing every gun crime incident or even just NFS in every city proved impossible. The crime incident reviews increased the strategic and tactical understanding of gun violence at each site. For example, Detroit's reviews revealed that the proportion of gun violence attributable to violent street group members was smaller than observed in other cities that have deployed the Ceasefire strategy. In all three cities, the reviews have indicated that individuals involved in prior NFS as suspects, victims, and witnesses appear to be at high risk for future involvement in NFS and GH. 
Creating a strategic understanding of gun violence helped inform tactical operations and resource deployment across sites. Review meetings often revealed immediate situations that could have resulted in further gun violence absent timely intervention by one of the participants such as retaliatory shootings against victims or witnesses. The reviews helped each site collect information specific to the local context and interest of the stakeholders (i.e., group and gang involvement, repeat individuals, prevention). Related, the incident reviews helped create a better understanding of the drivers of gun violence. This, in turn, created an environment that built shared commitment to addressing gun violence. While more difficult to quantify, accountability, coordination of efforts, cooperation, and service delivery all improved at the agency level. And, although cause and effect is difficult to disentangle, the simple act of meeting on a regular basis to review specific cases appeared to facilitate a shared commitment to addressing the lethal carnage discussed at each meeting.

\section{Challenges}

All four sites had long histories of actively working with researchers. As a result of this project, systematic gun crime data collection including NFS is occurring in all four sites and three of the four sites are conducting incident reviews. Collecting data and conducting reviews presented challenges, sometimes different, across the sites. Yet, while often time consuming, these challenges did not prove insurmountable for any of the sites and generally improved over time. Challenges to conducting gun crime incident reviews fell into three broad categories: people, systems, and resources.

People

Garnering support across multiple agencies to participate in the review process can be difficult. Commitment to the review process at the executive level was paramount not just for participation 
but for the required access to collect data and prepare for meetings. Concerns about resources, time commitment, and value of the reviews were constant for every agency. All sites reported an ebb and flow to the support for the review process and various challenges along the way related to gaining and maintaining support.

Engaging the right people to attend review meetings and bring available data were consistent challenges across sites. This was especially important as it related to the sharing of agency street-level information at meetings, that is, information not available in formal records management systems. And, as documented, the incident review process required heavy participation from law enforcement (Table 3). Often this required relying on specific officers (investigators, intelligence officers, etc.) to bring their knowledge and understanding of the individuals involved in the gun violence and the local context to the meetings. Meetings where 'key' individuals were not present often limited information sharing. Not having the right people at the meetings to respond to questions or act on the information presented often created frustration among partners because a primary goal of the meetings was to foster and identify opportunities for agency level action. For example, shared information about a problem house where the landlord seems unaware of the ongoing issues might create an opportunity for an invitation to landlord training or a mailed letter advising the landlord of the multiple police runs to the location. Similarly, information about an ongoing dispute involving dangerous individuals provides an opportunity for violence prevention but only if acted upon.

While staff turnover is quite common in police departments, it was exasperated by budget challenges, particularly in light of recent economic decline, and upper level staffing changes at all sites. Changes in administrations can both help and hurt project momentum. Staff changes resulted in frequent turnover among review meetings. Turnover also reduced the institutional 
knowledge of the process and, in some cases, lead to a decline in buy-in among key partners. The review staff repeatedly communicated the importance and value of the review process. Staff turnover at the ground level also made it more difficult to acquire street-level intelligence for the incident reviews. At the same time, there were instances of staff turnover that resulted in renewed commitment and enthusiasm for the review process.

And intertwined within all the people challenges is the issue of trust and personnel turnover created related challenges. As information sharing is the crux of the incident review meeting, participants must trust the others in the room in order to share information they would not normally share outside their own office workplace with people they would not normally share. Revealing details that are relevant to the review process but could also compromise a detective's case requires a significant amount of trust. Indeed, a 'visitor' to an incident review meeting could change the meeting dynamics enough to affect information sharing and effectively silence some participants. New participants may want to 'sit back and watch' for a few meetings before sharing information. Simple awareness of potential trust issues (see, for example, Rojek, Smith, and Alpert 2012, Rojek, Martin, and Alpert 2015, Braga and Hinkle 2010) as well as careful selection (or uninviting) of meeting participants is essential.

Systems

The review process was dependent on the access to data. Because the existing records systems at all four sites did not readily allow for extraction of NFS data and other non-GH crime, each had to create a mechanism to manually do this. Indeed, data collection of NFS proved to be equally challenging across all sites. As experience will support, figuring out how to collect accurate data that are not readily available electronically involves both art and science and each site accomplished this differently. Police departments are still the gatekeepers to the most 
informative data and each one is different. For this project, researchers needed access to more than just official records. And, it took time to get access, even with long time existing relationships in place. Each site had a research team, that is, not a single researcher, which usually meant records access was needed for more than one person. Background checks and indepth screening were common and took time and resources.

Initially, the incident review process at each location led to frequent requests for 'new' information. For instance, discussions about an individual's criminal history might lead to a request for probation or parole status or perhaps incarceration history. These requests for additional information resulted in the identification of information gaps. In one site, the gang unit had been inactive for a period and gang intelligence was stored in paper format only. In another site, the criminal history database that the city had used for over 15 years was replaced by a new program that did not afford the same information in the same way. Data validity and reliability were questionable as the bugs were still being worked out in the new system.

And, in some cases, the data systems did not support questions that were being asked. For example, information about gang involvement or 'gang related' crime has proven difficult to capture systematically and reliably across the sites. Information on disputes, which drive a lot of the gun violence (Wilson, MacDonald, and Tita 2010), is also hard to cull from police records management systems. Repeat individuals at different incidents, especially when not the victim or suspect, was important to review attendees but difficult to document outside of the reviews.

Related, sites encountered unexpected legal obstacles relating to the discussion and use of criminal history data for both adults and juveniles. In one case, it took about six months and a series of meetings to obtain formal permission to access and discuss records. In another site, the research team worked with team members to find a suitable substitution using police records 
management systems while working towards formal approval of state criminal history records. Finally, efforts are being made to increasingly utilize technologies such as National Integrated Ballistics Information Network (NIBIN) data and ShotSpotter data. However, in several sites, NIBIN is primarily used for forensics evidence as opposed to timely intelligence and ShotSpotter data are new or not available and therefore neither has enhanced the information sharing in the incident reviews.

Resources

Similar to the experience of police departments adopting Community-Oriented and ProblemSolving Policing (Greene 2004), attendees regularly had to balance every day demands like case investigations, court appearances, supervising clients, etc. with the time commitment of preparing for the reviews, attending the reviews, and acting upon the reviews. Police departments and partnering agencies considering the costs and benefits of implementing reviews need to consider the resource demands.

The time to prepare for reviews varied across sites. Pre-meeting communications can be difficult given the number and variety of people involved and work schedules. As described above, all of three of the cities participating in the reviews benefited from the participation of research partners who helped prepare information for the reviews. Absent such research partners, crime analysts could play this role, although the neutrality afforded by the researcher would be lost. Some sites used PowerPoint presentations to help guide the meetings and discussion which required considerable time to prepare. Gathering, analyzing, and summarizing the information from reviews similarly involved an expenditure of human resources.

Finally, if the reviews are executed as they are intended, more often than not, they create more work for individuals and agencies through case follow-up and operationalization on 
information presented. Indeed, one of the observations across the three cities was that the perceived value of the reviews was often connected to the actionable intelligence generated therein. One telling example involved an automated teller machine (ATM) location that generated regular robberies, some of which included shootings. This pattern of offenses revealed in the reviews led to a lieutenant working with the bank that owned the ATM to limit the hours of operation with the goal of eliminating an apparent 'crime attractor' during high risk periods. Although in the long-term this likely reduced calls for police service, in the short-term this required an additional set of responsibilities for this particular lieutenant. All of these activities (preparation, review, post-review actions), in turn, place pressure on people and systems in what are typically resource constrained environments.

\section{Discussion}

The incident reviews implemented in three of the study sites represented an innovative analytical approach to support problem solving efforts intended to address the significant issue of gun violence. This study of the incident review process suggested that reviews represent a supplemental source of information to the picture of gun crime captured in police records management systems. Incident reviews have the potential of tapping into street level intelligence existing within the police department as well as with other partnering organizations. This can increase the strategic understanding of gun violence, for example to what extent is gun violence being driven by gangs, disputes, intimate partner violence, drug markets, repeat locations, felons in possession of a firearm, or other factors? Correspondingly, incident reviews can increase the tactical understanding of current factors that may be driving violence such as active disputes among known groups; active chronic violent offenders; or incidents likely to generate retaliatory violence. 
Achieving the promise of problem solving to address gun violence generally, or the goals of the incident reviews specifically, requires changes at the organizational and interorganizational levels. Indeed, increased "coupling” (Duffee 1980, Wright 1981) within and across organizations appears to be an important element of problem solving and incident reviews. This is reflected in the findings of the present study. In all three jurisdictions, the reviews brought together actors within the police department from various units and levels of the organization. Likewise, in all three sites the reviews involved collaboration, including police departments, state and/or federal law enforcement, prosecutors, corrections agencies, and other stakeholders. Rather than collaborating simply through the processing of cases, the reviews involved a common focus on problems, in this case gun crime.

The current study suggests that, similar to other criminal justice innovations (Feeley 1983, Rosenbaum 1986, Skogan and Hartnett 1997, Skogan et al. 1999), implementing crime incident reviews is difficult. Research indicates there are key dimensions that need to be present in order for successful implementation to occur (McGarrell and Hipple 2014) and this is likely to be the case for successful implementation of incident reviews. These dimensions include commitment and leadership, partnerships, data availability and sharing, and communication and training. Indeed, the importance of all four dimensions was evident in these three sites.

Commitment and leadership was critical for launching the incident reviews; for enlisting the participation of key people, units, and agencies; and for sustaining participation over time. In all three sites there were vacillations in participation but clear evidence that when key organizational leaders placed a priority on gun violence, problem solving, and the importance of the reviews, that the participation, preparation, sharing of information, and quality of information coming from the incident reviews was significantly enhanced. Similarly, all three sites 
experienced times when such commitment was not apparent and the reviews yielded more limited benefits.

The importance of the partnerships was also critical. As noted above, this involved people and the establishment of trust to share information openly in the inter-organizational context of the reviews. Partnerships were also affected by the commitment and leadership dimension as it was critical to have the right people from the partnering units and agencies bringing and sharing information.

McGarrell and Hipple (2014) posit that a core dimension of effective implementation of problem solving is the quality and access of data to support meaningful problem analysis. The incident reviews represented a concrete technique for expanding the ability to analyze gun crime. All four jurisdictions engaged in new efforts to collect information about NFS with the three jurisdictions implementing incident reviews seeking to add to the basic picture of gun violence found in police incident reports by tapping into street level intelligence and multiple agency sources of information about the people, groups, places, and contexts driving gun crime.

One of the additional challenges of implementation mentioned by McGarrell and Hipple (2014), particularly when implementation is dependent on multiple units within an organization as well as inter-organizational partnerships, is the development of effective communication and training mechanisms. This related particularly to the 'people' challenges described earlier. Specifically, there was a need to create shared understanding of the purpose of the incident reviews, the dependency on preparation and participation by various actors involved in the reviews, and for sustaining this shared understanding in light of inevitable turnover.

In addition to continued study of these implementation dimensions, several additional research questions arose in this study. Whereas three of the four jurisdictions implemented crime 
incident reviews, each did so differently, tailoring them to their local context. This was reflected in the variations across the three jurisdictions on focal crimes (NFS, GH, all gun crime), geographic scope, all incidents versus select incidents, and similar elements. Although various advantages and disadvantages were apparent to the researchers (see Table 4), future research should address the trade-offs from the perspective of the participating agencies and the personnel involved in the reviews.

Moreover, a future goal of this research is to contrast the potential benefits of increased knowledge of patterns of gun violence yielded by incident reviews, weighing the concomitant costs and time requirements of this program, with data generated through existing information systems. Thus, St. Louis serves as a quasi-control site in the current analysis. From a theoretical perspective, the goal is to better understand if and how incident reviews offer unique insights into patterns of gun violence when compared to analyses of traditional police records management system. From a practical perspective, we hope to learn if the reviews generate tactical and strategic understanding of gun violence that can shape violence prevention and control strategies.

As noted at the beginning of this article, this project was funded by a grant from the National Institute of Justice. And, while all three sites implementing the reviews had initiated the reviews prior to the actual project period, grant funding supplemented the review process, made detailed data collection possible at all four sites, as well as funded research team involvement. It is impossible to ignore the role external funding plays in the development of multi-agency efforts like crime incident reviews and more broadly, police practitioner researcher partnerships (see, for example, Bales et al. 2014, Grieco, Vovak, and Lum 2014, Rojek, Smith, and Alpert 2012). This is not to say that incident reviews cannot be implemented without external or additional funding, 
rather, it makes it all the more important that the necessary organizational elements are in place for successful implementation and long-term sustainability (McGarrell and Hipple 2014).

Lastly, there is always the issue of sustainability of the data collection and review processes. Milwaukee has sustained the review process since inception in 2006. Detroit and Indianapolis have had periods of time with and without reviews occurring. St. Louis is still exploring the review process. The people, systems, and resources challenges presented here are both micro- and macro-level organizational issues that will most likely wax and wane over time and create difficulties not just for the review process itself but for overall sustainability. Maintaining support "at the top" through political and departmental turnover is essential to sustainability. While the review process may continue during periods of less support, sites may not necessarily get what they need in terms of people, systems, and other resources. The need for financial support cannot be ignored. Sustainability discussions must include enhanced data collection methods and their automation which are expensive but must be weighed against declining resources to support sworn personnel. Both experienced sites and sites new to crime incident reviews must be vigilant and proactive in anticipating and responding to challenges related to sustainability.

\section{Conclusion}

This research suggests the promise of gun crime incident reviews for supporting problem solving approaches to address the serious issue of gun violence. The expansion of incident reviews beyond homicides to include NFS, and in the case of Detroit additional gun crimes, significantly adds to the picture of gun violence and increases opportunities to identify the patterns of people, groups, places, and contexts driving gun violence in each of the cities. This contributes to the basic understanding of gun violence within each city and across cities, provides a strategic 
analysis to inform evidence-based prevention and control strategies, and offers tactical understanding for timely prevention and enforcement. Fulfilling the promise of the incident reviews, however, requires internal organizational and cross-agency inter-organizational collaboration to align people, systems, and resources with this proactive, problem-solving model. Additionally, effectively implementing these organizational and inter-organizational changes appears dependent on commitment and leadership, collaboration and partnerships, data quality and availability, and training and communication within and across organizational boundaries. Continued attention to these organizational, inter-organizational, and implementation dimensions appears as important to the integration of incident reviews in strategic problem solving initiatives as is the substantive understanding of gun crime that emerges from the reviews themselves. 


\section{References}

Allen, Rhonda Y.W. 2002. "Assessing the impediments to organizational change: A view of community policing." Journal of Criminal Justice 30 (6):511-517. doi: 10.1016/S00472352(02)00173-3.

Azrael, Deborah, Anthony A. Braga, and Mallory E. O'Brien. 2013. Developing the capacity to understand and prevent homicide: An evaluation of the Milwaukee Homicide Review Commission: Harvard School of Public Health.

Bales, William D., Samuel J.A. Scaggs, Catie L. Clark, David Ensley, and Philip Coltharp. 2014. "Researcher-practitioner partnerships: A case of the development of a long-term collaborative project between a university and a criminal justice agency." Criminal Justice Studies 27 (3):294-307. doi: 10.1080/1478601X.2014.947807.

Braga, Anthony A. 2008. Problem-oriented policing and crime prevention. 2nd ed. Monsey, NY: Criminal Justice Press.

Braga, Anthony A., and Marianne Hinkle. 2010. "The participation of academics in the criminal justice working group process." In The new criminal justice: American communities and the changing world of crime control, edited by John M. Klofas, Natalie Kroovand Hipple and Edmund F. McGarrell, 114-120. New York, NY: Routeledge.

Braga, Anthony A., David M. Kennedy, Elin J. Waring, and Anne M. Piehl. 2001. "Problemoriented policing, deterrence, and youth violence: An evaluation of Boston's operation ceasefire." Journal of Research in Crime and Delinquency 38 (3):195-225. doi: 10.1177/0022427801038003001.

Braga, Anthony A., and David L. Weisburd. 2006. "Problem-oriented policing: The disconnect between principles and practice." In Police innovation: Contrasting perspectives, edited by David L. Weisburd and Anthony A. Braga, 133-154. New York: Cambridge University Press.

Braga, Anthony A., and David L. Weisburd. 2010. Policing problem places: Crime hot spots and effective prevention. New York, NY: Oxford University Press.

Braga, Anthony A., David L. Weisburd, Elin J. Waring, Lorraine Green Mazerolle, William Spelman, and Francis Gajewski. 1999. "Problem-oriented policing in violent crime places: A randomized controlled experiment." Criminology 37 (3):541-580. doi: 10.1111/j.1745-9125.1999.tb00496.x.

Capowich, George E., and Janice A. Roehl. 1994. "Problem-oriented policing: Actions and effectiveness in San Diego." In The challenge of community policing: Testing the promises, edited by Dennis Rosenbaum, 127-146. Thousand Oaks, CA: Sage.

Cordner, Gary W., and Elizabeth Perkins Biebel. 2005. "Problem-oriented policing in practice." Criminology \& Public Policy 4 (2):155-180. doi: 10.1111/j.1745-9133.2005.00013.x.

Creswell, John W. 2012. Qualitative inquiry and research design: Choosing among five approaches. Thousand Oaks, CA: Sage publications.

Duffee, David. 1980. Explaining criminal justice: Community theory and criminal justice reform. Cambridge, MA: Oelgeschlager, Gunn and Hain Publishers, Inc.

Eck, John E., and William Spelman. 1987. Problem-solving: Problem-oriented policing in Newport News: US Department of Justice, National Institute of Justice.

Federal Bureau of Investigation. 2015a. "2013 National Incident-Based Reporting System." U.S. Department of Justice Accessed November 30, 2015. https://www.fbi.gov/aboutus/cjis/ucr/nibrs/2013/data-tables/\#Agency_Tables_by_State. 
Federal Bureau of Investigation. 2015b. Crime in the United States, 2014. Washington, DC: United States Department of Justice.

Feeley, Malcolm M. . 1983. Court reform on trial: Why simple solutions fail. New York: Basic Books, Inc.

Goldstein, Herman. 1979. "Improving Policing: A Problem-Oriented Approach." Crime \& Delinquency 25 (2):236. doi: 10.1177/001112877902500207.

Goldstein, Herman. 1990. Problem-oriented policing. New York, NY: McGraw-Hill, Inc.

Greene, Jack R. 2004. "Community policing and organization change." In Community policing (Can it work)?, edited by Wesley G. Skogan, 30-53. Belmont, CA: Wadsworth.

Grieco, Julie, Heather Vovak, and Cynthia Lum. 2014. "Examining research-practice partnerships in policing evaluations." Policing 8 (4):368-378. doi: 10.1093/police/pau03.

Hasenfeld, Yeheskel. 1972. "People processing organizations: An exchange approach." American Sociological Review 37 (3):256-263.

Hasenfeld, Yeheskel, and Paul P.L. Cheung. 1985. "The juvenile court as a people-processing organization: A political economy perspective." American Journal of Sociology 90 (4):801-824.

Hawken, Angela, and Mark Kleiman. 2009. Managing drug involved probationers with swift and certain sanctions: Evaluating Hawaii’s HOPE. Washington, DC: U.S. Department of Justice, National Institute of Justice.

Henry, Kelli, and Dana Kralstein. 2011. Community Courts: The research literature. New York, NY: Center for Court Innovation.

Hutchins, Ellen, Holly Grason, and Arden Handler. 2004. "FIMR and other mortality reviews as public health tools for strengthening maternal and child health systems in communities: Where do we need to co next?" Maternal and Child Health Journal 8 (4):259-268. doi: 10.1023/B:MACI.0000047424.62781.0d.

Klofas, John M., Natalie Kroovand Hipple, Jack McDevitt, Timothy S. Bynum, Edmund F. McGarrell, and Scott H. Decker. 2006. "Project Safe Neighborhoods: Strategic interventions crime incident reviews: Case Study 3." In Project Safe Neighborhoods: Strategic Interventions. Washington, DC: U.S. Department of Justice, Office of Justice Programs.

Klofas, John M., Natalie Kroovand Hipple, and Edmund F. McGarrell. 2010. The new criminal justice: American communities and the changing world of crime control. Edited by Chester Britt, Shaun Gabbidon and Nancy Rodriguez, Criminology and justice studies series. New York, NY: Routledge.

Loftin, Colin. 1986. "Assaultive violence as a contagious social process." Bulletin of the New York Academy of Medicine 62 (5):550.

Loftin, Colin, David McDowall, Karise Curtis, and Matthew D. Fetzer. 2015. "The accuracy of supplementary homicide report rates for large US Cities." Homicide Studies 19 (1):6-27. doi: $10.1177 / 1088767914551984$.

Maxfield, Michael G. 1989. "Circumstances in supplementary homicide reports: variety and validity." Criminology 27 (4):671-696. doi: 10.1111/j.1745-9125.1989.tb01050.x.

McGarrell, Edmund F., Steven Chermak, Jeremy Wilson, and Nicholas Corsaro. 2006. "Reducing homicide through a "lever-pulling" strategy." Justice Quarterly 23 (2):214231. doi: 10.1080/07418820600688818.

McGarrell, Edmund F., Nicholas Corsaro, Natalie Kroovand Hipple, and Timothy S Bynum. 2010. "Project safe neighborhoods and violent crime trends in US cities: Assessing 
violent crime impact." Journal of Quantitative Criminology 26 (2):165-190. doi: 10.1007/s10940-010-9091-9.

McGarrell, Edmund F., and Natalie Kroovand Hipple. 2014. "Developing evidence-based crime prevention practice: The dimensions of effective implementation." The Journal of Criminal Investigation and Criminology 65 (4):249-258.

Miller, Alden D., Lloyd E. Ohlin, and Robert B. Coates. 1977. A theory of social reform: Correctional change processes in two states. Cambridge, MA: Ballinger Publishing Company.

Mitchell, Ojmarrh, David B. Wilson, Amy Eggers, and Doris L. MacKenzie. 2012a. "Assessing the effectiveness of drug courts on recidivism: A meta-analytic review of traditional and non-traditional drug courts." Journal of Criminal Justice 40 (1):60-71. doi: 10.1016/j.jcrimjus.2011.11.009.

Mitchell, Ojmarrh, David B. Wilson, Amy Eggers, and Doris L. MacKenzie. 2012b. "Drug courts' effects on criminal offending for juveniles and adults." Campbell Systematic Reviews 8 (4).

National Research Council. 2005. "Committee to Improve Research Information and Data on Firearms." In Firearms and violence: A critical review, edited by Charles F. Wellford, John V. Pepper and Carol V. Petrie. Washington, DC: The National Academies Press.

O'Brien, Mallory, Laurie Woods, and Ron A Cisler. 2007. "The Milwaukee Homicide Review Commission: An interagency collaborative process to reduce homicide." Wisconsin Medical Journal 106 (7):385.

Riedel, Marc. 1990. "Nationwide homicide datasets: An evaluation of UCR and NCHS data." In Measuring crime: Large-scale, long-range efforts edited by Doris L. MacKenzie, Pyyllis J. Baunach and Roy R. Roberg, 175-208. Albany, NY: State Unviersity of New York Press.

Roehl, Janice A., Dennis P. Rosenbaum, Sandra K. Costello, J. Coldren, A. Schuck, Laura Kunard, and D Forde. 2008. Paving the way for project safe neighborhoods: SACSI in 10 US Cities: US Department of Justice, Office of Justice Programs, National Institute of Justice.

Rojek, Jeff, Peter Martin, and Geoffrey P. Alpert. 2015. "Research partnerships as a form of knowledge translation." In Developing and maintaining police-researcher partnerships to facilitate research use, 1-25. New York, NY: Springer.

Rojek, Jeff, Hayden P. Smith, and Geoffrey P. Alpert. 2012. "The prevalence and characteristics of police practitioner-researcher partnerships." Police Quarterly:241-261. doi: $10.1177 / 1098611112440698$.

Rosenbaum, Dennis P. 1986. Community crime prevention: Does it work? Beverly Hills, CA: Sage Publications.

Sevigny, Eric L., Brian K. Fuleihan, and Frank V. Ferdik. 2013. "Do drug courts reduce the use of incarceration?: A meta-analysis." Journal of Criminal Justice 41 (6):416-425. doi: 10.1016/j.jcrimjus.2013.06.005.

Skogan, Wesley G., and Susan M. Hartnett. 1997. Community policing, Chicago style. New York, NY: Oxford University Press.

Skogan, Wesley G., Susan M. Hartnett, Jill DuBois, Jennifer T. Comey, Marianne Kaiser, and Justine H. Lovig. 1999. On the beat: Police and community problem solving. Boulder: Westview Press. 
Tilley, Nick. 1999. "The relationship between crime prevention and problem-oriented policing." In Problem-Oriented Policing: Crime-specific problems, critical issues and making POP work, edited by C.S. Brito and T. Allan Washington, D.C.: Police Executive Research Forum.

Toch, Hans, and J. Douglas Grant. 1991. Police as problem solvers. New York: Penum Press.

Williams, Kirk R., and Robert L. Flewelling. 1987. "Family, acquaintance, and stranger homicide: Alternative procedures for rate calculations." Criminology 25 (3):543-560. doi: 10.1111/j.1745-9125.1987.tb00810.x.

Wilson, Jeremy M., John M. MacDonald, and George E. Tita. 2010. "Localized homicide patterns and prevention strategies: A comparison of five Project Safe Neighborhood sites." Victims \& Offenders 5 (1):45-63. doi: 10.1080/15564880903423060.

Wright, Kevin N. 1981. "The desirability of goal conflict within the criminal justice system." Journal of Criminal Justice 9 (3):209-218. doi: 10.1016/0047-2352(81)90070-2. 
Table 1. Violent crime and homicides in project sites

\begin{tabular}{|c|c|c|c|c|c|}
\hline & $\underline{\text { Detroit }}$ & $\underline{\text { Indianapolis }}$ & $\underline{\text { Milwaukee }}$ & $\underline{\text { St. Louis }}$ & $\begin{array}{c}\text { National } \\
\text { Average MSA }\end{array}$ \\
\hline \multicolumn{6}{|l|}{2014 Violent Crime } \\
\hline Total & 13,616 & 10,768 & 8,864 & 5,348 & \\
\hline Rate per 100,000 people & 1988.6 & 1254.7 & 1476.4 & 1678.7 & 395.7 \\
\hline Rank Order - Cities with more than 250,00 people & 6 & 9 & 10 & 22 & \\
\hline \multicolumn{6}{|l|}{2014 Homicide } \\
\hline Total & 298 & 136 & 86 & 159 & \\
\hline Rate per 100,000 people & 43.5 & 15.8 & 15.0 & 49.9 & 4.7 \\
\hline Rank Order - Cities with more than 250,00 people & 2 & 18 & 20 & 1 & \\
\hline
\end{tabular}


Table 2. Project site summary

\begin{tabular}{|c|c|c|c|c|}
\hline & Detroit & Indianapolis & Milwaukee & St. Louis* \\
\hline $\begin{array}{l}\text { Crime incident review } \\
\text { Geographic scope }\end{array}$ & 2 precincts & City-wide & City-wide & City-wide \\
\hline $\begin{array}{l}\text { Gun homicide } \\
\text { Data collection }\end{array}$ & City-wide & City-wide & City-wide & City-wide \\
\hline $\begin{array}{l}\text { Non-fatal shooting } \\
\text { Data collection }\end{array}$ & City-wide & City-wide & City-wide & City-wide \\
\hline $\begin{array}{l}\text { Gun homicide } \\
\text { Crime incident reviews }\end{array}$ & Yes & No & Yes- all homicides & - \\
\hline $\begin{array}{l}\text { Non-fatal shooting } \\
\text { Crime incident reviews }\end{array}$ & Yes & Yes & Yes & - \\
\hline Case selection for reviews & $\begin{array}{c}\text { All GH and NFS cases } \\
\text { occurring in } 2 \\
\text { precincts }\end{array}$ & NFS - triage selection & $\begin{array}{c}\mathrm{GH}-\text { all } \\
\mathrm{NFS}-\text { triage } \\
\text { selection }\end{array}$ & - \\
\hline Meeting frequency & Weekly & Monthly & $\begin{array}{c}\text { GH - Monthly } \\
\text { NFS - Bi-weekly }\end{array}$ & - \\
\hline Meeting length & 90 minutes & 2 hours & 2 hours & - \\
\hline Number of cases reviewed & $\begin{array}{l}\text { 20-25 gun incidents } \\
\text { 3-6 CCW arrests }\end{array}$ & Up to 8 NFS & $\begin{array}{l}\text { Up to } 8 \text { Homicides } \\
\text { NFS - varies }\end{array}$ & - \\
\hline Meeting preparation & $\begin{array}{l}\text { Case summaries } \\
\text { sent } 2 \text { days prior }\end{array}$ & $\begin{array}{c}\text { Case list sent } 1 \text { week prior } \\
\text { PowerPoint }\end{array}$ & GH- PowerPoint & - \\
\hline Meeting Location & Police Department HQ & Police district HQ & $\begin{array}{l}\text { GH - Department } \\
\text { of Corrections } \\
\text { NFS - Rotating } \\
\text { district HQ }\end{array}$ & - \\
\hline Case presentation & $\begin{array}{l}\text { Precinct Lieutenant for } \\
\text { case }\end{array}$ & $\begin{array}{c}\text { Aggravated } \\
\text { Assault/Robbery Unit } \\
\text { Sergeant }\end{array}$ & $\begin{array}{c}\text { GH- Homicide } \\
\text { Unit Lieutenant } \\
\text { NFS - District } \\
\text { Personnel }\end{array}$ & - \\
\hline
\end{tabular}

*St. Louis did not intend to implement gun crime incident reviews 
Table 3. Agency review participation by site

\begin{tabular}{|c|c|c|c|}
\hline & Detroit & Indianapolis & Milwaukee \\
\hline \multicolumn{4}{|l|}{ Federal Partners } \\
\hline USAO & $\mathrm{R}$ & & $\mathrm{R}$ \\
\hline FBI & $\mathrm{O}$ & & $\mathrm{R}$ \\
\hline ATF & $\mathrm{R}$ & & $\mathrm{R}$ \\
\hline Probation & $\mathrm{R}$ & $\mathrm{R}$ & $\mathrm{R}$ \\
\hline \multicolumn{4}{|l|}{ State Partners } \\
\hline State Police & $\mathrm{R}$ & & \\
\hline DOC & $\mathrm{R}$ & & $\mathrm{R}$ \\
\hline Fusion Center & & $\mathrm{R}$ & $\mathrm{O}$ \\
\hline \multicolumn{4}{|l|}{ Local Partners } \\
\hline Mayor's Office & $\mathrm{R}$ & & \\
\hline Police Department* & $\mathrm{R}$ & $\mathrm{R}$ & $\mathrm{R}$ \\
\hline Prosecutor's Office & $\mathrm{R}$ & $\mathrm{R}$ & $\mathrm{R}$ \\
\hline Sheriff’s Office/Jail & & $\mathrm{O}$ & $\mathrm{O}$ \\
\hline Probation/Parole & $\mathrm{R}$ & $\mathrm{R}$ & $\mathrm{R}$ \\
\hline Community Corrections & $\mathrm{R}$ & $\mathrm{R}$ & $\mathrm{R}$ \\
\hline Crime Lab & & $\mathrm{R}$ & \\
\hline Nuisance Abatement & & $\mathrm{R}$ & \\
\hline School Police & $\mathrm{O}$ & & $\mathrm{R}$ \\
\hline Research Team & $\mathrm{R}$ & $\mathrm{R}$ & $\mathrm{R}$ \\
\hline Civilian Coordinator & $\mathrm{R}$ & & $\mathrm{R}$ \\
\hline Outreach Coordinator & $\mathrm{R}$ & & $\mathrm{R}$ \\
\hline \multicolumn{4}{|l|}{ *Police Department Participants } \\
\hline Command-level officers & $\mathrm{R}$ & $\mathrm{O}$ & $\mathrm{O}$ \\
\hline Homicide Unit & $\mathrm{O}$ & $\mathrm{R}$ & $\mathrm{R}$ \\
\hline Aggravated Assault/Robbery Unit & & $\mathrm{R}$ & \\
\hline Street-level/front line officers & $\mathrm{R}$ & $\mathrm{R}$ & $\mathrm{R}$ \\
\hline Gang Unit & $\mathrm{R}$ & $\mathrm{R}$ & \\
\hline Intelligence Unit & $\mathrm{R}$ & $\mathrm{R}$ & \\
\hline Juvenile Unit & & $\mathrm{R}$ & \\
\hline Precinct-level special operations & $\mathrm{R}$ & & $\mathrm{R}$ \\
\hline
\end{tabular}

$\mathrm{R}=$ Regular participation

$\mathrm{O}=$ Occasional participation 
Table 4. Incident review dimensions

\begin{tabular}{|c|c|c|}
\hline DIMENSION & Advantages & $\underline{\text { Disadvantages }}$ \\
\hline \multicolumn{3}{|l|}{ Geographic scope } \\
\hline Citywide & Comprehensive picture & Resource intensive \\
\hline Police district(s) & $\begin{array}{l}\text { Easier to implement } \\
\text { (resource-wise); } \\
\text { Easier to tap into street-level } \\
\text { knowledge }\end{array}$ & $\begin{array}{l}\text { Limited generalizability; } \\
\text { potential to miss cross-district } \\
\text { elements }\end{array}$ \\
\hline \multicolumn{3}{|l|}{ Crime scope } \\
\hline All gun crimes & $\begin{array}{l}\text { Comprehensive picture; ability } \\
\text { to observe escalation and } \\
\text { connections across cases }\end{array}$ & Resource intensive \\
\hline Homicides \& NFS & $\begin{array}{l}\text { Ability to see connections } \\
\text { across most serious gun } \\
\text { violence }\end{array}$ & $\begin{array}{l}\text { May miss patterns to other violent } \\
\text { crime }\end{array}$ \\
\hline Homicide only & $\begin{array}{l}\text { Easier to implement } \\
\text { (resource-wise) }\end{array}$ & $\begin{array}{l}\text { Miss majority of cases involving } \\
\text { gun injury }\end{array}$ \\
\hline NFS only & $\begin{array}{l}\text { Expands focus to all cases } \\
\text { involving gun injury }\end{array}$ & $\begin{array}{l}\text { May miss connections to } \\
\text { homicides }\end{array}$ \\
\hline \multicolumn{3}{|l|}{ Case selection } \\
\hline All GH and NFS & $\begin{array}{l}\text { Opportunity to make } \\
\text { connections across all cases }\end{array}$ & Time and resource intensive \\
\hline $\begin{array}{r}\text { Triage selection } \\
\text { Meeting freguency }\end{array}$ & Time efficient & May miss cross-case connections \\
\hline$\frac{1}{\text { Weekly }}$ & $\begin{array}{l}\text { Timely tactical information for } \\
\text { intervening to prevent gun } \\
\text { violence }\end{array}$ & $\begin{array}{l}\text { Resource intensive; limited } \\
\text { investigatory information }\end{array}$ \\
\hline Monthly & $\begin{array}{l}\text { More detailed information from } \\
\text { investigations and background } \\
\text { information gathering }\end{array}$ & $\begin{array}{l}\text { Limits ability for timely tactical } \\
\text { prevention responses }\end{array}$ \\
\hline \multicolumn{3}{|l|}{ Visual Aides } \\
\hline PowerPoint & $\begin{array}{l}\text { Detail specific; can enhance } \\
\text { discussion }\end{array}$ & Time and resource intensive \\
\hline
\end{tabular}

